\title{
Linfoma no Hodgkin y carcinomatosis peritoneal: una imagen a recordar
}

\author{
Non-Hodgkin lymphoma and peritoneal carcinomatosis: \\ an image to remember
}

José Felipe Reoyo-Pascual ${ }^{1}$, Carlos Cartón-Hernández ${ }^{1}$, Guillermo Cabriada-García ${ }^{1}$, Raquel León-Miranda ${ }^{1}$, Gregorio Moral-Moral ${ }^{1}$ y Francisco Javier Sánchez-Manuel ${ }^{1}$

Los LNH presentan frecuentemente afectación extranodal. Sin embargo, la afectación peritoneal en forma de implantes es infrecuente.

Presentamos el caso de una mujer de 48 años que debido a abdominalgia inespecífica se diagnostica de esplenomegalia indeterminada, con estudios hematológicos anodinos. El TC preoperatorio no aportaba otros datos de interés.

Se realiza esplenectomía objetivando bazo de 20 $\mathrm{cm}$ con superficie parcheada por implantes blanquecinos que no recordaban a la afectación típica linfomatosa (Figura 1) que se distribuían también por el espacio supramesocólico, tomando biopsias de los mismos. El estudio anatomopatológico reveló linfoma folicular difuso. Actualmente la paciente recibe tratamiento quimioterápico evolucionando satisfactoriamente.

En conclusión, ante el hallazgo intraoperatorio de implantes peritoneales, se ha de incluir entre los posibles diagnósticos, la aparición de un linfoma no Hodgkin.
'Servicio de Cirugía General y del Aparato Digestivo, Hospital Universitario de Burgos. Burgos, España.

Recibido el 29 de marzo de 2018, aceptado para publicación el 25 de abril de 2018

Correspondencia a: Dr. Jose F. Reoyo-Pascual Avda. Islas Baleares s/n, Burgos, España. jreoyo@saludcastillayleon.es

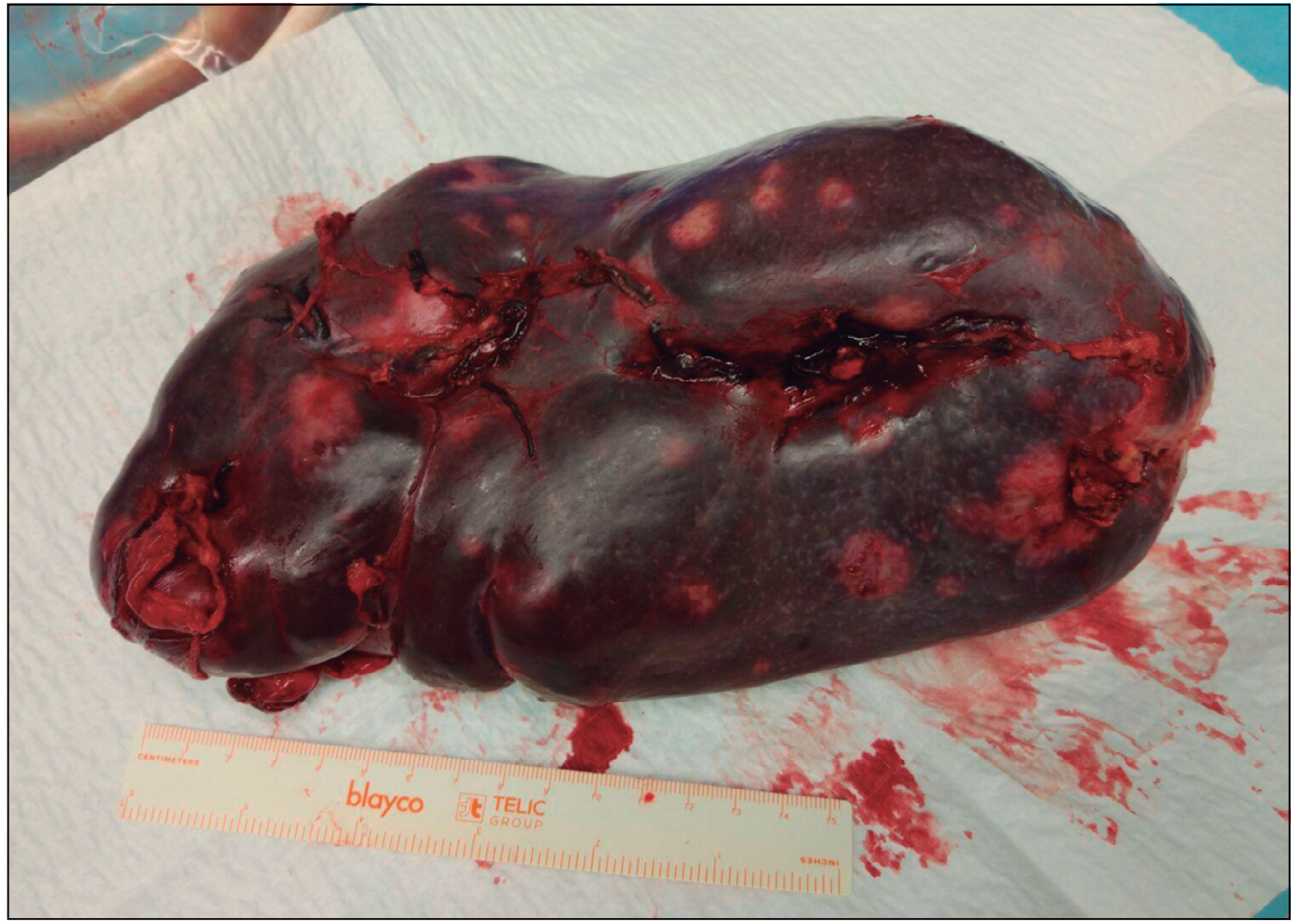

Figura 1. Imagen de la pieza quirúrgica (esplenectomía) donde se observan punteados blanquecinos que pueden simular carcinomatosis peritoneal. 


\section{Responsabilidades éticas}

Protección de personas y animales. Los autores declaran que para esta investigación no se han realizado experimentos en seres humanos ni en animales.

Confidencialidad de los datos. Los autores declaran que en este artículo no aparecen datos de pacientes.

Derecho a la privacidad y consentimiento informado. Los autores declaran que en este artículo no aparecen datos de pacientes.
Conflictos de interés: no hay.

\section{Referencias}

1. Carro I, Alegre N, Cervera JL, Montero AI. Manifestaciones Radiológicas de la afectación extranodal del linfoma. Radiología 1998;40:321-5.

2. Krudy A, Dunnick N, Magrath I, Shawker T, Doppman J, Spiegel R. CT of American Burkitt lymphoma AJR 1981;136:474-54. 